\title{
HET MAUSOLEUM VAN ISABELLA VAN OOSTENRIJK († 1526) IN DE GENTSE SINT-PIETERS ABDIJKERK
}

\author{
door
}

\author{
R.A.C. VAN DRIESSCHE
}

Isabella of Elisabeth van Oostenrijk, jongste zuster van Keizer Karel V, werd vermoedelijk op 18 juli 1501 te Brussel geboren ${ }^{1}$. Samen met de andere kinderen van Filips de Schone werd ze opgevoed aan het Hof van haar tante, Margareta van Oostenrijk. Op veertienjarige leeftijd werd Isabella uitgehuwelijkt aan Christiaan II, Koning van Denemarken, Zweden en Noorwegen. Filips van Bourgondië, de latere bisschop van Utrecht, scheepte op 14 juli 1515 te Veere in met de bruid op weg naar haar nieuw vaderland ${ }^{2}$.

Haar huwelijk én haar drievoudige kroon brachten Isabella echter weinig vreugde. In 1523 brak tegen haar losbandige en wispelturige echtgenoot een revolutie uit zodat het gezin zijn heil zocht in de vlucht. De zwerftocht van de onfortuinlijke Isabella eindigde te Zwijnaarde in het kasteel van de Sint-Pietersabdij waar ze op 19 januari 1526, amper 25 jaar oud, ter ziele ging. Ze liet een zoon, Jan, die kort nadien overleed, en twee dochters, Dorothea en Christine, achter. Met grote luister werd ze te Gent voor het hoogaltaar in de Sint-Pieters abdijkerk begraven.

Cornelis de Schepper, humanist, diplomaat en vertrouweling van het Deens Huis, stelde in ronkend latijn haar grafschrift op ${ }^{3}$. Christiaan II zal nu al het mogelijke doen om - aan zijn zo jong ontslapen gade een waardig grafmonument te bezorgen.

Steunend op de autoriteit van Marcus van Vaernewyck (1518-1569), werd dit monument tot circa 1920 unaniem beschouwd als zijnde van de hand van de Mechelaar Jan de Heere die zich te Gent had gevestigd ${ }^{4}$. P. Bergmans leverde echter het bewijs dat de uitvoering werd toevertrouwd

(1) Over de juiste geboortedag van Isabella bestaat er betwisting. Volgende data worden opgegeven: J.F. WILLEMS, Isabella van Oostenrijk, Belgisch Museum voor de Nederduitsche Taelen Letterkunde en de Geschiedenis des Vaderlands, II, Gent 1838, p. 196: 18 juli; PH. KERVYN DE VOLKAERSBEKE, Les églises de Gand, II, Gent 1858, p. 237: 16 juli; E. VARENBERGH, Elisabeth ou Isabelle d'Autriche, Biographie Nationale, Vi, Brussel 1878, p. 544 : 18 juli; V. VAN DER HAEGHEN, Exhumation des cendres d'Isabelle d'Autriche, Messager des sciences historiques, Gent 1886, p. 19 : 19 juli ; M. DERUELLE, Het grafmonument van Isabelle van Oostenrijk te Gent, Kunst IV, Gent 1933, p. 130: 18 juli; G. DE BOOM, Destins tragiques des Habsbourg au XVle siècle, Ysabeau d'Autriche et Don Carlos, Brussel 1946, p. 9: 17 juli.

(2) J. DUVERGER, Jacopo de Barbari en Jan Gossart bij Filips van Bourgondië te Souburg (1515), Mélanges Hulin de Loo, Brussel-Parijs 1931, p. 8.

(3) M. VAN VAERNEWYCK, Die warachtighe Historie... van Carolus de Viffste, Gent 1564, $f^{\circ} \mathrm{Or}^{\circ}$ - O iij $\mathrm{r}^{\circ}$ : Ch. DIERICX, Mémoires sur la ville de Gand 1814-1816, aanhangsel, pp. 182-188; J.F. WILLEMS, o.c., p. 231; E. DE BUSSCHER, L'Abbaye de Saint-Pierre à Gand, Gent 1847, pp. 68-69.

(4) M.J. ONGHENA, Jan de Heere, Nationaal Biografisch Woordenboek, II, Brussel 1966, kol. 294-305. 
aan het duo Jan de Smytere en M. de Smet. De ontdekking van Bergmans werd later bevestigd en gestaafd met documenten uit het Rijksarchief van Kopenhagen ${ }^{5}$.

Het oudst bekende kontrakt werd op 9 februari 1526 gesloten tussen de koning en Willem Dedelinc die belast werd met de uitvoering van de latoenen grafplaat volgens "t uutwijzen van der ghescrifte" (patroon) van de beroemde schilder Jan van Mabuse. Toen ontving Dedelinc een eerste betaling ${ }^{6}$. Volgens Duverger zou Jan Gossart van Mabuse het huwelijkskonvooi vergezeld hebben. Mabuse werkte later trouwens samen met Jacopo de Barbari aan de decoratie van de bisschopsresidentie van Filips van Bourgondië te Souburg op het eiland Walcheren. Ook Adolf van Bourgondië, neef van Filips en mecenas van Mabuse zou van het gezelschap deel hebben uitgemaakt ${ }^{7}$.

Het volgend kontrakt, gesloten op 14 februari 1526, tussen de vorst en Jan de Smytere gaat over de albasten omlijsting die, eveneens naar het patroon van Mabuse, een "werck van anticaigen" (renaissance) moest worden ${ }^{8}$.

De uitvoering van de opdracht bleef achterwege zodat de koning op 9 juni 1526 bij Margareta van Oostenrijk ging aankloppen om borg te willen staan voor de uitgaven ${ }^{9}$. Er kwam inderdaad geen schot in het werk. De Smytere had in Antwerpen wel albast besteld maar kon het materiaal niet krijgen. Tot dan, op 7 september, het verschuldigd bedrag was toegezegd ${ }^{10}$.

Op 20 september 1526 verklaarde De Smytere, beeldsnijder te Gent, dat hij 300 Rijnsgulden aan provisie had ontvangen voor het te maken grafschrift ${ }^{11}$ en op 6 maart 1527 schrijft Hans Mikkelsen aan zijn broodheer Christiaan II over de uitbetaling aan Jan Gossart van Mabuse en aan de steenhouwers van Gent ${ }^{12}$. Dat de Smytere aan de tombe liet werken door Matheus de Smet weet men uit de betaling van 5 maart $1528{ }^{13}$.

Sedert de dood van Isabella waren er nu reeds vele maanden verlopen zonder dat het werk vorderde. Glarbo meent daaruit te mogen besluiten

(5) P. BERGMANS, Jean de Smytere, Biographie Nationale, XXII, Brussel, 1914-20, kol. 886-887; H. GLARBO, Droning Elisabeths Gravmaele i Gent, Kunstmuseets Aarsskrift, XIIIXV, Kopenhagen 1929-1930, pp. 67-69.

(6) H. GLARBO, o.c., p. 74; cf. R.A. Kopenhagen, Münchersamlingen 59; D.1-2. Met dank aan het R.A. Kopenhagen dat ons de foto's van de originele documenten heeft bezorgd.

(7) J. DUVERGER, o.c., l.c.; M. DERUELLE, De St.Pietersabdij te Gent, Gent 1933, pp. 96, 99, 100.

(8) M. DERUELLE, o.c., p. 100 (leest verkeerdelijk "antiraige"); R.A. Kopenhagen, Münchersamlingen, nr. 61; cfr. H. Glarbo, o.c., p. 61; M. Deruelle, o.c., pp. 100-101.

(9) R.A. Kopenhagen, Münchersamlingen, p. 75.

(10) H. GLARBO, o.c., p. 75; R.A. Kopenhagen, Münchersamlingen, papir 65/1526; M. DERUELLE, o.c., p. 101.

(11) H. GLARBO, o.c., pp. 75-76; M. DERUELLE, o.c., p. 101; R.A. Kopenhagen, Münchersamlingen, papir 262/1528.

(12) H. GLARBO, o.c., p. 78.

(13) M. DERUELLE, o.c., p. 97 (De Smet moest zijn eigen werk "beteren"); S.A. Gent, Jaarregister Keure, 1527-1528, fo 128. 
dat De Smytere zich aan afpersing zou bezondigd hebben ${ }^{14}$. Gezien de benarde financiële toestand van de vorst zijn we eerder geneigd te geloven dat er wegens geldgebrek getalmd werd met de uitvoering van het grafmonument van de koningin. Wat er ook moge gebeurd zijn, De Smytere heeft op 13 juni 1528 nogmaals 100 gulden ontvangen ${ }^{15}$.

In het kontrakt van 14 februari 1526 tussen Christiaan II en Jan de Smytere staat dat bij het voortijdig overlijden van De Smytere, zijn "cnape" Jan de Heere het monument moet voltooien ${ }^{16}$. We zijn van oordeel dat de leertijd van De Heere toen zo goed als beëindigd zal geweest zijn. De talentvolle "cnape" had in die tijd trouwplannen of was misschien reeds gehuwd met Anna, de dochter van zijn meester. De Smytere is overleden vóór 6 augustus 1528 (cf. infra). Het praalgraf van Isabella van Oostenrijk is dan ook het oudst bekende belangrijke werk van Jan de Heere.

Hans Mikkelsen schreef op 17 juni 1528 aan de koning dat alles klaar was om de tombe op te stellen maar dat dit niet kon gebeuren omdat Mabuse, belast met de "visitering", zou overleden zijn ${ }^{17}$. Dit klopt niet met de werkelijkheid. Inderdaad uit een brief die abt Gerard van Cuelsbroeck op 6 augustus 1528 aan de koning schreef blijkt dat Mabuse niet overleden was, wèl daarentegen Jan de Smytere ${ }^{18}$. Mabuse bleef trouwens tot aan het einde van zijn dagen (1 oktober 1532) in dienst van Mencia de Mendo$\mathrm{za}$, gade van Hendrik III van Nassau te Breda ${ }^{19}$.

Op 14 augustus 1528 meldde de abt aan de koning die toen te Antwerpen verbleef, de ontvangst van 150 gulden ter voltooiing van het grafmonument ${ }^{20}$. Uit die gelden betaalde de abt twee dagen later aan Dedelinc 6 ponden groot als provisie voor het grafschrift ${ }^{21}$.

Het geduld van Koning Christiaan II was ondertussen blijkbaar ten einde, want, op 20 augustus daaropvolgend meldde hij de prelaat dat hij over enkele dagen persoonlijk naar Gent zou komen om er te spreken met Mabuse en met de meester die in Zeeland werkzaam was ${ }^{22}$. Dat het hier meester Jan de Heere betreft blijkt uit het antwoord van de prelaat ( 25 augustus 1528); hij had van Mabuse, vanuit Middelburg, bericht ontvangen dat er niet verder aan het monument kon gewerkt worden zolang De Heere te Mechelen zwaar ziek te bed lag ${ }^{23}$.

(14) H. GLARBO, o.c., p. 75.

(15) H. GLARBO, o.c., Pp. 75-76; A.R. Kopenhagen, Münchersamlingen, papir 262/1528.

(16) H. GLARBO, o.c., p. 74; M. DERUELLE, o.c., pp. 100-101: R.A. Kopenhagen, Münchersamlingen, nr. 61.

(17) M.J. ONGHENA, Jan Dheere, Nationaal Biografisch Woordenboek, II, Brussel 1966, kol. 924; H. GLARBO, o.c., p. 76; M. DERUELLE, o.c., p. 103 (stelt verkeerdelijk dat De Heere met de zuster van De Smytere getrouwd was).

(18) H. GLARBO, o.c., p. 77; M. DERUELLE, o.c., p. 102.

(19) E. DHANENS, Gossaert (genaamd Mabuse), Nationaal Biografisch Woordenboek, Brussel 1987, XII, kol. 319-320.

(20) H. GLARBO, o.c., p. 76; A.R. Kopenhagen, Münchersamlingen, papir 113/1528.

(21) H. GLARBO, o.c, A.R. Kopenhagen, Münchersamlingen, papir 56/1528; 55/1528.

(22) A.R. Kopenhagen, Münchersamlingen; M. DERUELLE, o.c., p. 102 maar zonder juiste bronvermelding; R.A. Gent, Varia III, autographes des personnages remarquables.

(23) H. GLARBO, o.c., p. 77; M. DERUELLE, o.c., p. 103 (uit die brief blijkt nochtans niet dat De Heere het werk zou laten bezichtigen); A.R. Kopenhagen, Münchersamlingen, papir 114/1528). 
Schipper Gillis de Bucq heeft in oktober 1528 het laatste albast ontscheept. Enkele maanden later, nl. op 2 februari 1529, werd aan de zuidzijde van het koor het grafschrift gemonteerd daar waar "tghescrift ende epitaphum altooes gehanghen heeft". Het verving blijkbaar een geschilderd dito dat, onmiddellijk of kort na de begrafenis van de koningin, was aangebracht. Het is mogelijk dat de afbeelding hiervan identiek was aan de afbeelding voorkomend op de keerzijde van de tekening van de koperen grafplaat (afb. 2).

In een brief van 25 maart 1529 waarin abt van Cuelsbroeck rekenschap gaf aan Christiaan II van de gelden die hij onlangs van de koning ontvangen had ter voltooiing van het grafmonument, sprak hij zijn oprechte bewondering uit voor het inmiddels voltooide mausoleum ${ }^{24}$.

Dank zij de goedwil van enkele gematigde personen ontsnapte het mausoleum aan de beeldenstorm die in 1566 als een lawine over onze gewesten trok. De Gentse patriciër Marcus van Vaernewyc - tijdgenoot van de feiten - heeft ons hierover enkele détails nagelaten ${ }^{25}$. Gedurende de tweede beeldenstorm die in augustus 1578 Gent zwaar teisterde ging dit unicum van onze vroegrenaissance beeldhouwkunst voor altijd verloren ${ }^{26}$.

Tijdens de bouw van de barokkerk onder Albrecht en Isabella werden het gebeente van de koningin en van haar zoon Jan in een voorlopig graf geplaatst (19 januari 1600). Pas op 16 april 1652 werden de gebeenten door abt Antonius Engrand processiegewijs in een nieuwe tombe bijgezet ${ }^{27}$

Op bevel van Keizerin Maria-Theresia werd het graf in 1764 opnieuw geopend. Op verzoek van minister graaf de Cobenzl, gedateerd 3 juli 1764, gericht aan abt Sieger werd toen om een tekening verzocht ${ }^{28}$. Dit belangrijk document blijft tot op heden onvindbaar.

In november 1796 werd de lodenbus, bevattend het proces - verbaal van hoger vermelde translatio, door de Franse soldateska geroofd. Uit de koperen grafplaat werden toen wetenschappelijke instrumenten gemaakt. Of het hier al dan niet ging om de oorspronkelijke grafplaat blijft een open vraag ${ }^{29}$.

De eerste pastoor van O.L.Vrouw-Sint-Pieters parochie, gewezen monnik van de St.-Pietersabdij, Emiel Malingié, verzamelde in 1814 piëteitsvol opnieuw het gebeente ${ }^{30}$.

(24) A.R. Kopenhagen, Münchenersamlingen, nrs. 126, 232, papir 111/1528; S.A. Gent, Atlas Goetghebuer, afzonderlijke bundel A. van Wijnendaele.

(25) M. VAN VAERNEWYC, De Historie van Belgis..., Gent 1574, IV, kap. XLVIII, fol. $199 \mathrm{v}^{\circ}$; M. DERUELLE, o.c., pp. 91-93; M. VAN VAERNEWYC, Van die beroerlicke tyden in die Nederlanden en voornaamlyc in Ghendt, I, Gent 1566, pp. 130-131, 149.

(26) J. VAN DEN VIVERE, Chronycke van Ghendt, uitgave F. de Potter, Gent 1885, p. 272; B. DE JONGHE, Gbendtsche geschiedenissen..., II, Gent 1871, pp. 42-44, 49-50, 93.

(27) E. MALINGIÉ, Livre de jours (13 aug. 1779-1793, I, Gent, Univ. bibl. hs. B.G. 11201,

p. 69; J.F. WILLEMS, Isabella van Oostenrijk, Belgisch Museum, 1838, pp. 234-235.

(28) E. MALINGIE, o.c., p. 18; R.A. Gent, Fonds St.-Pietersabdij, 2de reeks, nr. 100.

(29) J.F. LAVAL, Verzaemeling van ecbte en andere stukken betrekkelijk de stad Gend, II, Gent 1833, p. 31; V. VANDER HAEGHEN, Exhumation des cendres d'Isabelle d'Autriche, Messager des sciences historiques, Gent 1886, pp. 26-27.

(30) E. MALINGIE, o.c., pp. 276-277; J.F. WILLEMS, o.c., pp. 233-236. 
In 1851 stelde Kervyn de Volkaersbeke dat het de hoogste tijd was om de restanten van het mausoleum voor definitieve teloorgang te vrijwaren. In 1858 herhaalde hij "qu'il devient urgent de restaurer la trop modeste tombe de cette malheureuse reine" 31 .

Het stoffelijk overschot van Isabella en van haar zoon Jan werden in 1883 ontgraven. Naar Denemarken verscheept werden ze op 10 oktober van dat jaar in de St.-Knudskerk te Odense ter aarde besteld. Aan de hand van de akwarellen van Aerent van Wijnendaele zou dan een nieuw mausoleum worden gebouwd. Gezien de hoge kosten, inherent aan zulk projekt, bleef dit plan evenwel in de lade steken ${ }^{32}$.

Uit de archiefbronnen blijkt dat het mausoleum bestond uit drie welomschreven gedeelten : (1) het grafschrift, (2) de albasten omlijsting en (3) de tombe. Ontwerper was de geniale Gossaert van Mabuse. Uitvoerders : Willem Dedelinc, Jan de Smytere, M. de Smet en Jan de Heere.

Om enig idee te hebben over de vorm en het uitzicht van het in 1578 vernielde grafmonument verwijzen wij naar enkele bestaande afbeeldingen. De oudst bewaard gebleven tekeningen zijn de akwarellen van meester Aerent van Wijnendaele. Ze stammen uit circa 1560 en worden bewaard in de Atlas Goetghebuer op het Stadsarchief te Gent. Het betreft hier $1^{\circ}$ een tekening met het epitaaf (afb.1), uitgevoerd in bruine inkt, en op een blad papier geplakt. Goetghebuer schreef erbij "Arent van Wijnendaele, stedeschilder, del. 1560"; $2^{\circ}$ - op de versozijde staat het gekleurd ruitvormig blazoen van Isabella gehouden door twee gevleugelde engelen; in iedere hoek van het vierkantig, door een lijst omgeven blad, ziet men nog een gekroond wapenschild. Onderaan dit blad is de tombe afgebeeld verborgen onder een zwart fluwelen deken versierd met een gouden laken kruis zoals dit op de hoogdagen gebruikelijk was (afb. 2). De originele tekening die Van Wijnendaele van de tombe moet gemaakt hebben ontbreekt in deze collectie.

In 1768, meer dan twee eeuwen later, werd een kopie van deze tekening gemaakt door Jean-Baptist Weemaes. Deze zou nu in het British Museum te Londen berusten. Een andere kopie bevindt zich in hoger geciteerde Atlas (afb. 3) met een tekst die aansluit bij vorige beschrijvingen ${ }^{33}$.

Een andere tekening, in hoger geciteerde Atlas, geeft ons een beeld van het mausoleum dat in 1652 in de barokkerk werd opgericht (afb. 4).

In zijn boek "Die waerachtighe geschiedenisse ..... van Carolus de Vijfste" publiceerde Marcus van Vaernewijc in 1564 een gravure van de tombe (afb. 5). Volgens Kervyn de Volkaersbeke was dit de enige bekende afbeelding van vóór de Beeldenstormen. Deze afbeelding zou Aerent van Wijnendaele tot voorbeeld hebben gediend ${ }^{34}$. Wij zijn echter van oordeel dat juist het omgekeerde is gebeurd.

(31) PH. KERVYN DE VOLKAERSBEKE, Rapport sur l'état des monuments historiques et artistiques de la ville de Gand, Messager des Sciences Historiques, Gent 1851, p. 322; IDEM, Les églises de Gand, II, Gent 1858, p. 240.

(32) V. VANDER HAEGHEN, o.c., pp. 105-106; M. DERUELLE, o.c., p. 105.

(33) A.R. Kopenhagen, Münchersamlingen; S.A. Gent, atlas Goetghebuer, l.c.

(34) Ph. KERVYN DE VOLKAERSBEKE, Les églises de Gand, II, Gent 1858, pp. 218, 232. 


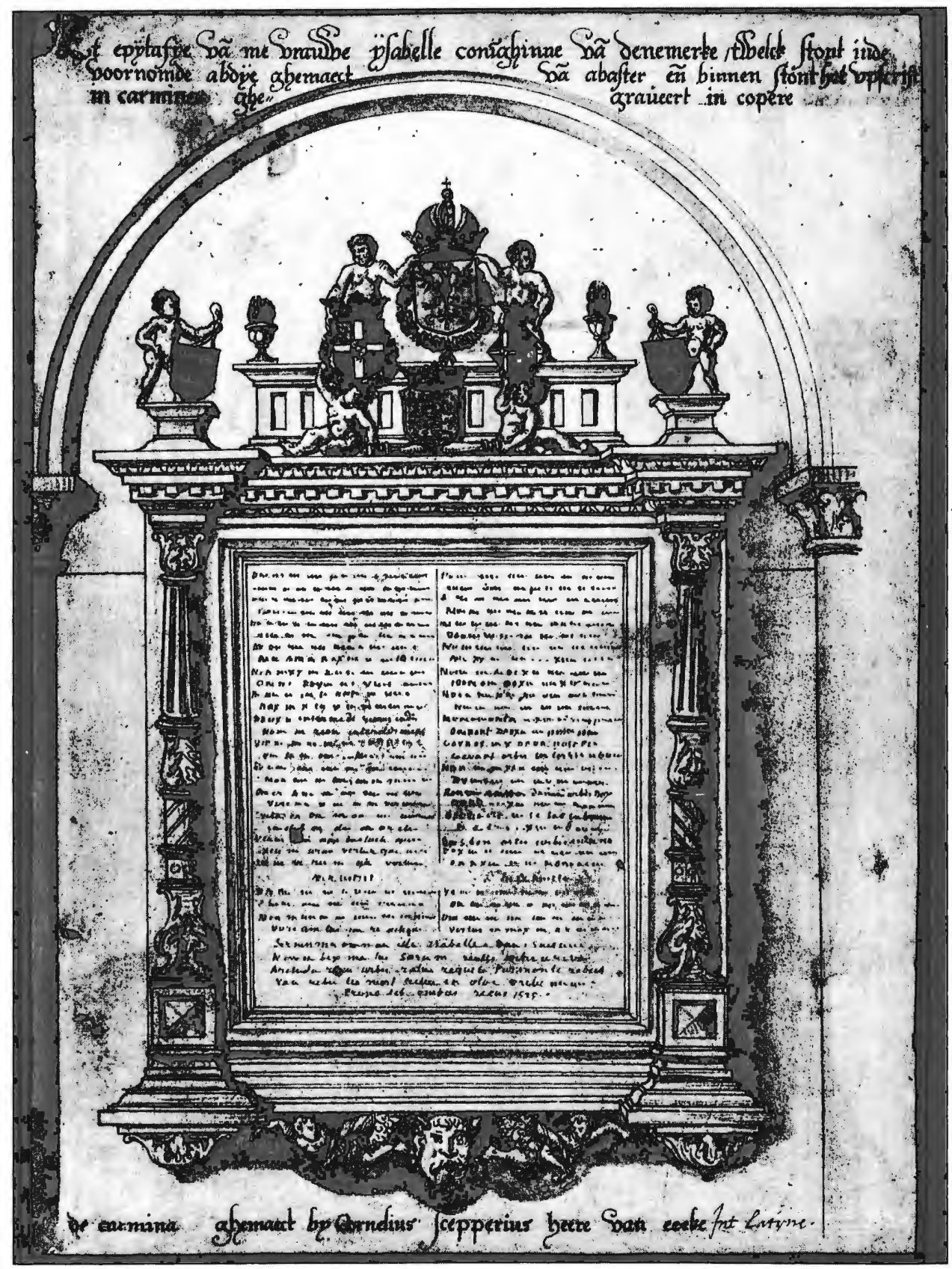

Afb. 1 - Arend van Wynendaele, Epitaaf Isabella van Oostenrijk, S.A.G., Atlas Goetghebuer. 


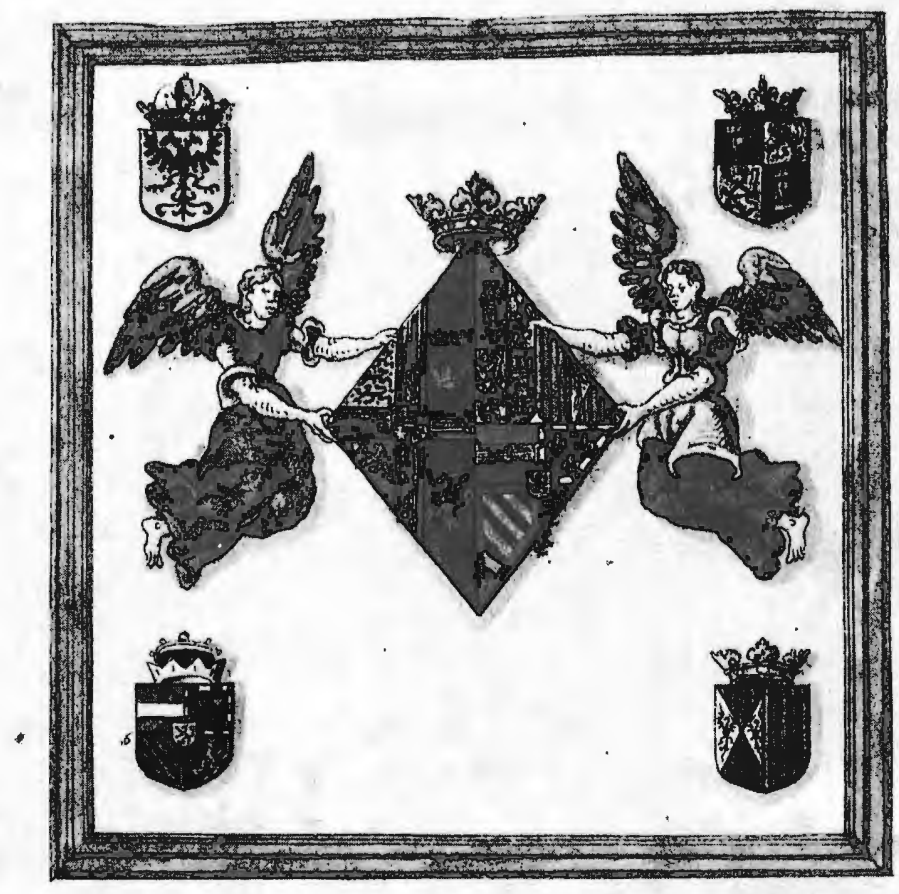

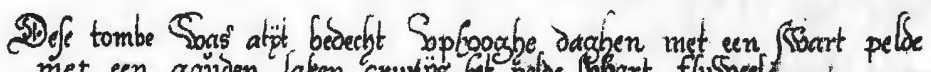
met een gauden laten cruxips Get peloe Jbart flusbeel

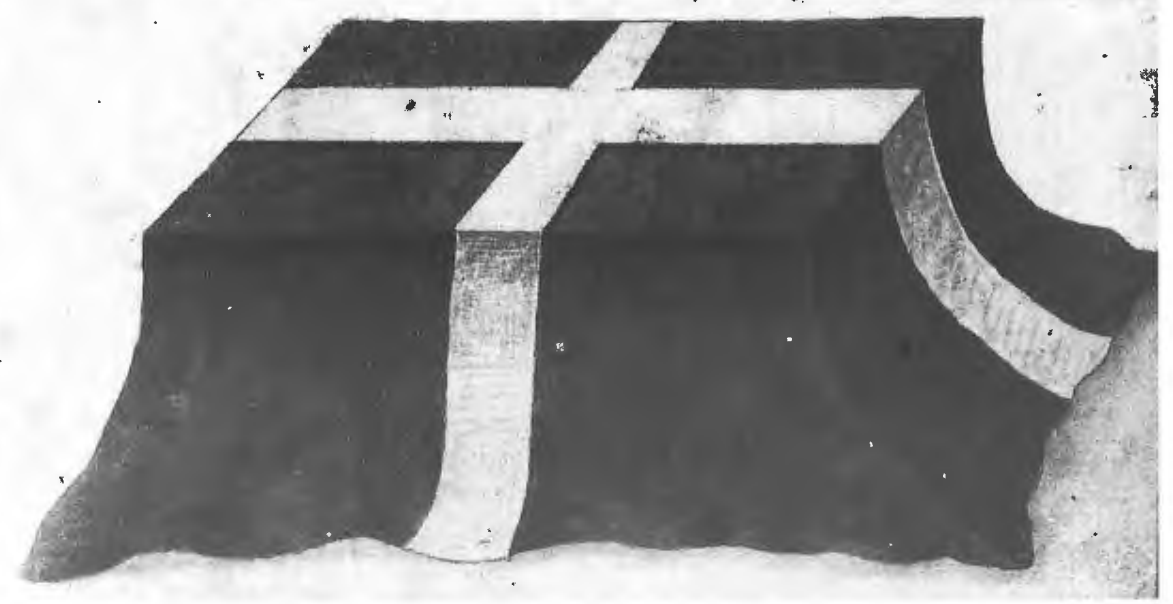

Afb. 2 - Arend van Wynendaele, Verso van afbeelding 1. 


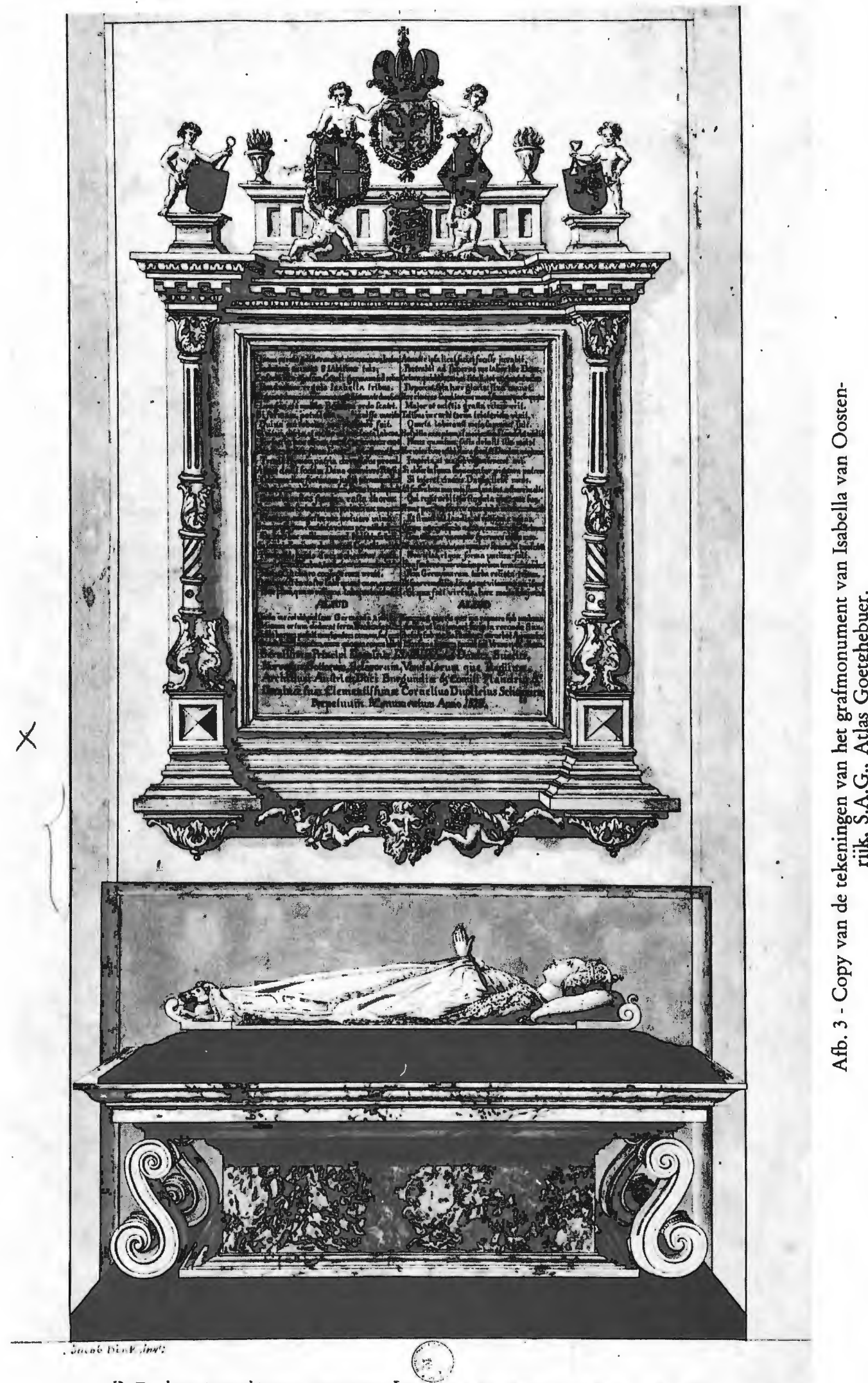

De Tombe on Fpitaphic van Mevrauwc ISA BELLE (coningiune van Denemerken \& deweleke font inde kereke der Abelyevan Sinte Pieters jemaeckt van Albalier, en binnen flont het opfchrift in defe Latynfelee Carmina iscóraverert op eene kopere Placte en gemaekt door den Edelen here ("ornelius. Duplieius Swepperus Heere van Bectie alwaer hy is begraven on tol op heden fyne waepenen en epitaphintum noch gefien wordf. 


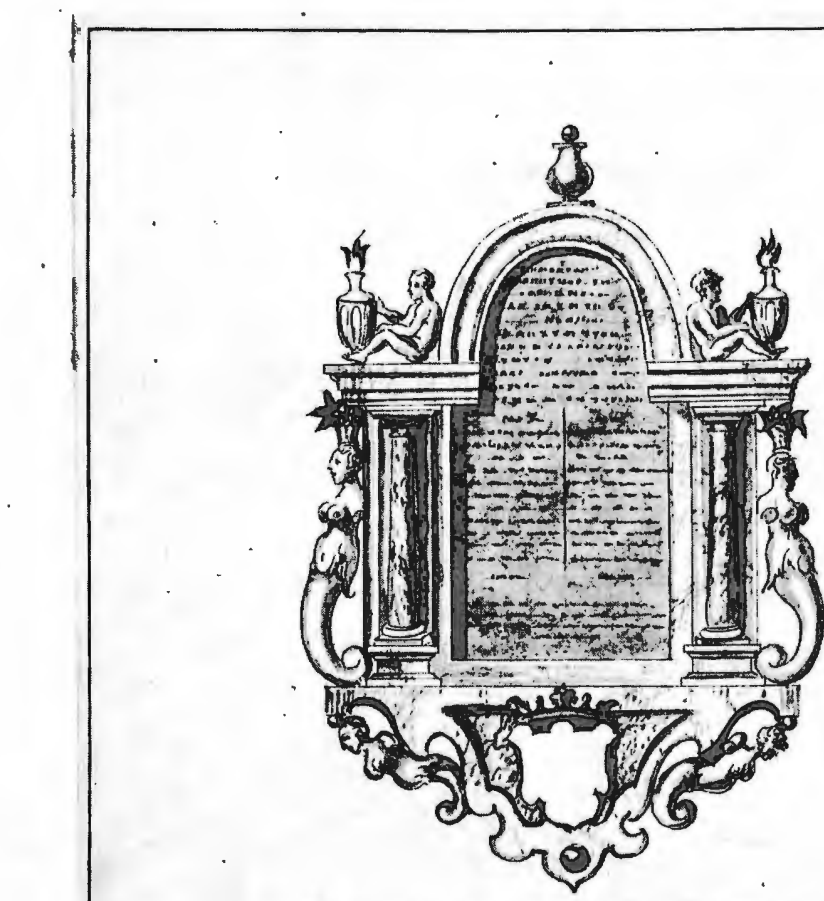

Epitaphie van vrau Isabelle Coningin. -ne van Deriemerken en zuster van Keyser Carolus den vyfden, ufen lalyne in't vlaemisch vertaelt by M. jo:van deVivere, voor den lykdienst op den xu februnary is 25 . in sinte Pieters Kercke te Chendt, alwaer $3 \mathrm{y}$ voor den booghen autaer begraevenleght.

De tambe van de Coninginne lsabelle welte in de nienwe gebaumde Abrlye herke van Sinte Pieters te Ghendt Geplaels is in't jaer 1652. deszelfs loode histe en de geane van haeren "yoon jaul, met zes schriften op' perkement wierden ex nytgerooft door de Fransche renolutionnairen in irgs, de overblyfsels wierden met zorge erzaemeld. in deze tombe den 24 myeizid. 

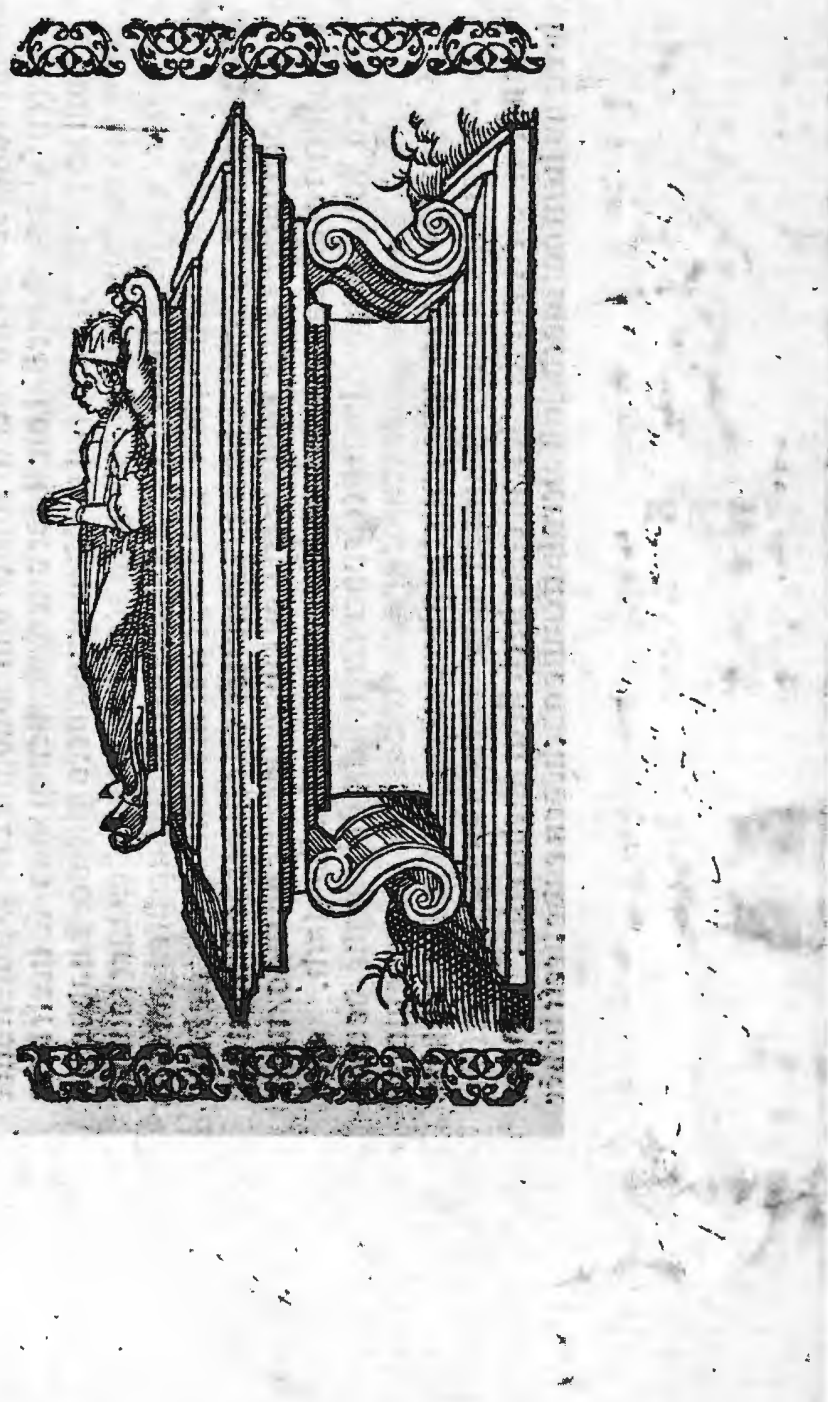

Afb. 5 - Gravure van de graftombe naar akwarel van A. van Wynendaele, Marcus van Vaernewyck, Die Waerachtighe Geschiedenisse van Carolus de Vijfste, Gent, 1564, p. O.j.vº. 


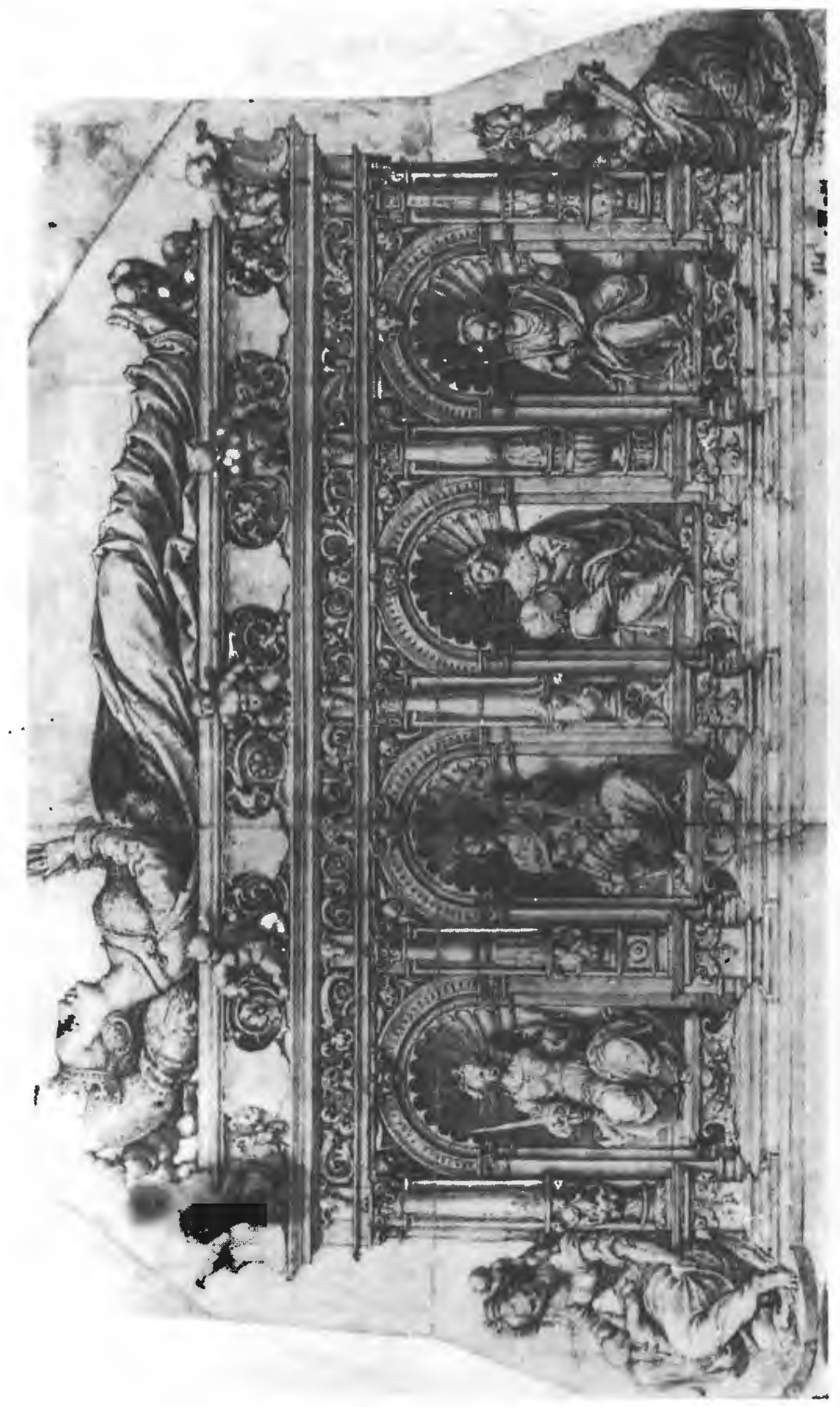

Afb. 6 - Vermoedelijk ontwerp van Mabuse voor het mausoleum van Isabella van Oostenrijk, Prentenkabinet Berlijn. 


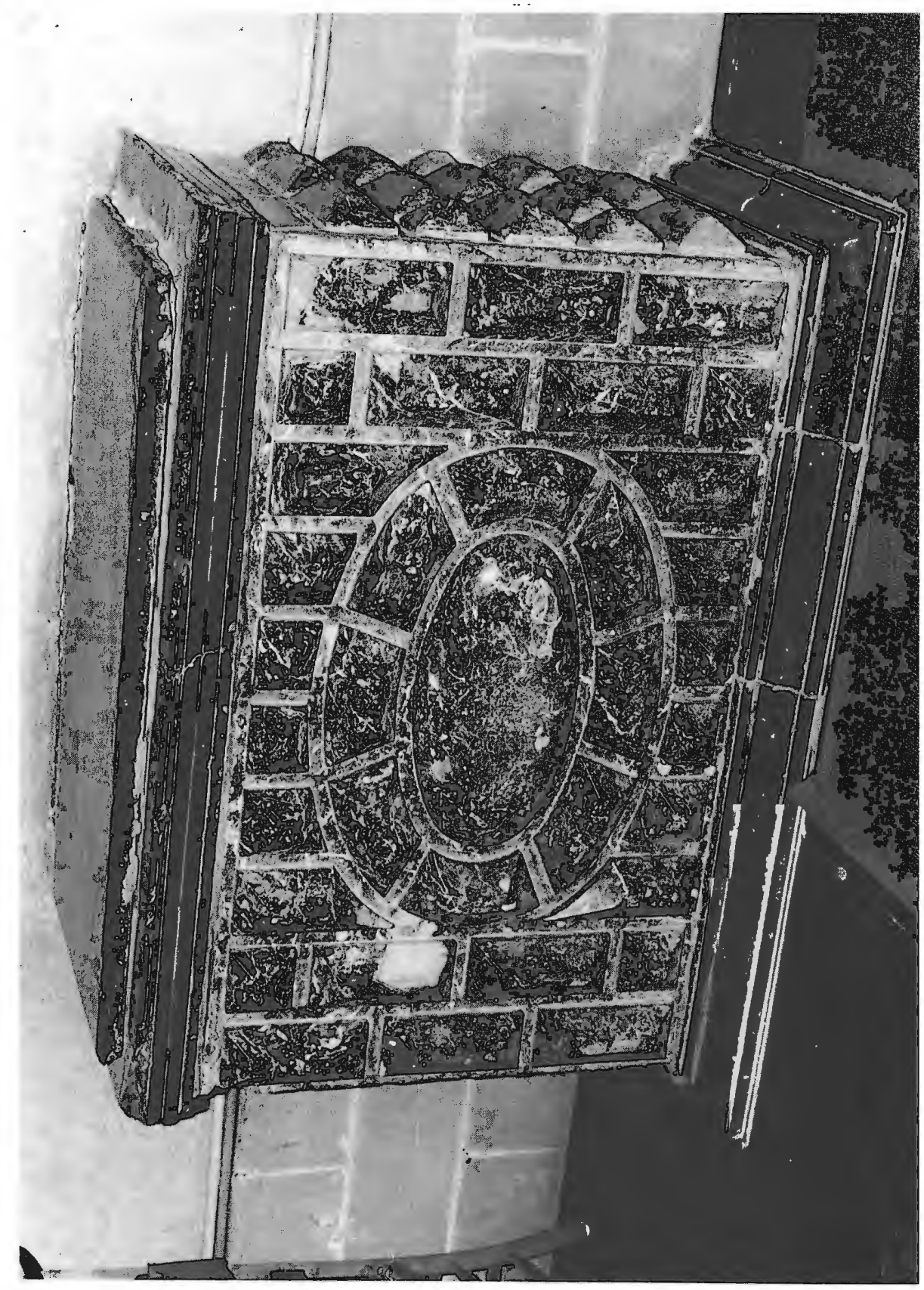

Afb. 7 - Huidige tombe van Isabella van Oostenrijk in de O.L. VrouwSt-Pieterskerk te Gent. 
Het epitaaf versierd met de kwartieren van Isabella, zonder de weelderige omlijsting, werd eveneens opgenomen in de grafschriftenverzameling Van Huerne die nog vóór de tweede Beeldenstorm werd samengesteld ${ }^{35}$.

Te oordelen naar de tekeningen (afb. 1,3) is de analogie met andere gekende werken van Jan de Heere overduidelijk ${ }^{36}$. De sokkel bestond uit een zwart-marmeren sterk geprofileerd lijstwerk waarboven de roodmarmeren tombe was aangebracht. Samen met vier zware albasten voluten - twee aan het hoofd - en twee aan het voeteinde - schraagde dit onderstel een flink uitkragende dekplaat. Het albasten beeld van de koningin rustte op een soort slede.

De houding is nog gotiserend: de handen devoot in gebed gevouwen, het hoofd getooid met de koningskroon, op een kussen aan de voeten de traditionele hazewind. Het lichaam is gehuld in een rijkelijk versierde mantel (afb. 3).

Volgens het kontrakt werd het grafschrift - op zwarte grond en in reliëf - op een latoenenplaat geslagen (afb. 1). De albasten omlijsting is een weelderig voorbeeld van vroegrenaissancekunst.

Aan weerskanten werd het epitaaf geflankeerd door een sierlijk kandelaberzuiltje, waarvan de schacht alternerend voorzien was van schuine en vertikele groeven, lijstwerk en akantusbladeren. De zuiltjes eindigden op gekoppelde saterpoten die neerkwamen op een vierkantig voetstuk; voorzien van een diamantkop steunden zij op het basislijstwerk. In het midden van dit lijstwerk stond een saterkop geflankeerd door zwevende putti en hoornen van overvlied en daarnaast, in de as van de zuiltjes, een akantusblad.

Als dekstuk fungeerde een entablement samengesteld uit drie welgescheiden lijsten voorzien met eier-tand-en bladlijstwerk. Dit dekstuk was getooid met een soort edikel en zes blazoenhoudende putti. Dit alles was gevat onder een triomfboog met gladde zuilen en akantuskapitelen.

Uitgevoerd in de meest uitgelezen bonte-marmers werd de sobere compositie van de tombe enigszins gemilderd door de vier zware voluten die, in zekere mate, als vroege voorlopers van de barok mogen bestempeld worden. Daarentegen vertoont het lijstwerk van het epitaaf alle kenmerken van de typisch rijke vroegrenaissance vormentaal.

Wij mogen niet nalaten de aandacht te vestigen op de anonieme pentekening (afb. 6) uit het Berlijnse Prentenkabinet ${ }^{37}$. Het gaat hier om een rijkelijk opgevat grafmonument waarvan de onderbouw omzet is met allegorische vrouwenfiguren en met als gisant een jonge vorstelijke vrouw. Die tekening wordt door sommige kunsthistorici beschouwd als het ontwerp dat Mabuse zou gemaakt hebben voor het grafmonument van Isabel-

(35) Grafschriften Van Huerne 16-17e eeuw, verzameling Baron Gilles de Pélichy: cfr. E. RENDERS, Hubert van Eyck, personnage de légende, Parijs-Brussel 1933, afb. 2 en 3.

(36) M.J. ONGHENA, o.c., kol. 296.

(37) P. CLEMEN, Lanceloot Bondeel und die Anfänge der Renaissance in Brügge, Belgische Kunstdenkmäler, München 1923, II, p. 5, afb. 3; H. PAUWELS, H.R. HOETINK en S. HERZOG, Tentoonstellingscatalogus Jan Gossaert genaamd Mabuse, Rotterdam-Brugge 1965, pp. 329-30; M. VANROOSE, De Beeldhouwkunst van de 16de eeuw, Gent, Duizend Jaar Kunst en Cultuur, I, Gent 1975, pp. 475-476. 
la van Oostenrijk. Wegens de overdadige weelderigheid, en de daaraan verbonden uitgaven, zou dit project geen doorgang hebben gevonden. De vrij eenvoudige opvatting van het uitgevoerd mausoleum (de tombe) zoals we die kennen uit de bewaard gebleven tekeningen strookt inderdaad niet met de exhuberante vormentaal van Mabuse waarmede de Berlijnse prent stylistisch nauwe verwantschap vertoont.

Sedert $1810^{38}$ is aan de graftombe van 1652 (afb. 4) - zoals die nu nog in de O.L.Vrouw-Sint-Pieterskerk staat (afb. 7) - niets veranderd. De opstaande wanden uit rood marmer zijn bezet met diamantkoppen. Het voetstuk en de dekplaat werden uitgevoerd in zwart-marmer met terugwijkend lijstwerk ${ }^{39}$. Zoals aan het grafmonument van Philibert van Savooie en Margareta van Oostenrijk te Brou, waarvan het definitief ontwerp werd toevertrouwd aan Jan van Room en het beeldhouwwerk o.m. aan Gillis van Belle, Conrat en Thomas Mijt, hebben ook hier meerdere kunstenaars samengewerkt ${ }^{40}$.

Als men in overweging neemt dat de rol van De Smijtere, De Smet, De Heere en Dedelinc zich beperkte tot de uitvoering van het ontwerp van Mabuse, is het, ons inziens, van weinig belang om zich verder te buigen over de taakverdeling van die meesters.

Voor de kunstvisie van De Heere én de ontplooiing van het Italianisme in de Lage Landen daarentegen moet de samenwerking én vooral het kontakt met Mabuse, die op het slot van Souburg met Jacobo de Barbari had gewerkt, van doorslaggevend belang zijn geweest. Voornamelijk in de omlijsting van het grafschrift was de stijl in harmonie met die van de dekoratieve architecturen die in de schilderijen van Mabuse veelvuldig voor$\mathrm{kwamen}$. Zijn modellen bezaten volume en streefden in de uitbeelding van de personen het plastisch-sculpturale na. Karel van Mander roemde Mabuse trouwens als de eerste Nederlandse Romanist, die in zijn vaderland niet enkel de Italiaanse vormentaal maar tevens de voorstelling van het naakt en de mythologische taferelen invoerde ${ }^{41}$.

In de rij van de vorstelijke praalgraven, zoals dit van Engelbert III van Nassau te Breda, van Willem de Croy te Heverlee (1528), van Antoon de Lalaing te Hoogstraten (vóór 1540) en van De Merode te Geel (1554), nam dit van Isabella van Oostenrijk in de Gentse St.-Pieterskerk dan ook een belangrijke plaats in.

(38) Archief van de Koninklijke Academie voor Schone Kunsten te Gent; C. PIOT, Rapport à Mr. le Ministre de l'Intérieur sur les tableaux enlevés à la Belgique en 1794 et restitués en 1815, Brussel 1883, pp. 193-208.

(39) R. VAN DRIESSCHE, De Sint-Pietersabdij te Gent. Archeologische en kunsthistorische studie. Mij Geschiedenis en Oudheidkunde te Gent, Gent 1980, p. 162.

(40) J. DUVERGER, Bijdrage en documenten tot de Kunstgeschiedenis, 2e reeks, Vorstelijke grafmonumenten wit bet begin der XVIe eeuw, Gent 1941, pp. 19-23; D. ROGGEN en S. LEURS, Vroegrenaissance bouw- en beeldhouwkunst, Geschiedenis van de Vlaamsche Kusnt I, Antwerpen zj., p. 512.

(41) J. GABRIELS, De vroeg renaissance in de schilderkunst, Geschiedenis van de Vlaamsche Kunst, I, Antwerpen, zj, p. 453. 